\title{
AS DIFERENCAS E AS PARECENÇAS ENTRE ALUNOS INDÍGENAS KRIKATI E NÃO INDÍGENAS NO C. E. PARSONDAS DE CARVALHO
}

\author{
ARAÚJO ${ }^{1}$, Karitânia dos Santos \\ Universidade Federal do Maranhão (UFMA)
}

\section{RESUMO}

O artigo apresentado aqui é sobre um projeto que visava inclusão e a melhoria da interação de estudantes indígenas da Etnia Krikati em uma escola não-indígena no município de Sítio Novo do Maranhão, no Estado do Maranhão. Discutimos sobre alteridade, identidade e as dificuldades enfrentadas pelo alunado Krikati, em razão da ineficiência do Estado de inserir o indígena no contexto escolar vigente.

Palavras chave: Diferença. Alteridade. Preconceito. Inclusão. Escola.

\section{ABSTRACT}

The article presented here is about a project aiming the inclusion and improving interaction of indigenous students - Krikati people - at nonindigenous school in the municipality of Sítio Novo do Maranhão, State of Maranhão, Brazil. Hereby We discuss alterity, identity and difficulties faced by Krikati students, in reason of State's inefficiency in matter of including these people into the general school context.

Key Words: Difference. Otherness. Preconception. Inclusion. School.

1 1. Especialista em Educação em Direitos Humanos (UFMA), Imperatriz, Maranhão. Email: setorindigena.itz@gmail.com SEDUC - MA, professora Mag. IV/ Técnica da Educação Escolar Indígena.

2. Coordenadora de Ação 'Saberes Indígenas na Escola'.

3. Licenciada em História pela Universidade Estadual do Maranhão, Imperatriz. 


\section{INTRODUÇÃO}

Com a criação da Aldeia Jerusalém, em 2012, na terra indígena Krikati, dentro dos limites do território do município de Sítio Novo, os alunos foram remanejados para as escolas deste município. E o C. E. Parsondas de Carvalho, de nível médio, ficou responsável por 17 alunos Krikati. No entanto, este espaço de construção de saberes não estava preparado para receber o público indígena, que encontrou sérias dificuldades para se adaptar ao ambiente escolar do não índio.

A sociedade em geral, mais especificamente a escolar, sofreu um grande impacto cultural. Nos primeiros meses de aula notou-se uma série de dificuldades desses discentes no processo de ensino aprendizagem, sendo a mais notória delas a língua. Diferentemente dos demais alunos que já têm dificuldades com algumas disciplinas, os da etnia Krikati, além das mesmas dificuldades, ainda têm que traduzir simultaneamente tudo o que o professor explicou e tentar entender o conteúdo, com o agravante da divergência entre a didática da aldeia e da cidade.

A escola precisaria de um PPP que contemplasse as especificidades do alunado Krikati. Outra dificuldade enfrentada é a falta de transporte. Nem todo dia o veículo da prefeitura vai buscálos e, por esse motivo, faltam muito às aulas. Não bastando todos esses problemas ainda precisam enfrentar o preconceito dos alunos, dos professores e da sociedade envolvente.

Durante quase 03 anos vivenciei essa experiência, através do ensino, na condição de professora de História, na cidade de Sítio Novo - MA. Acompanhei de perto os alunos indígenas e a repercussão da inserção dos mesmos na Escola do não índio. O preconceito velado estava impregnado na fala dos gestores, professores e demais alunos que eram a maioria. De imediato comecei a tentar desconstruir essa situação de exclusão.

Este projeto nasceu de uma conversa entre mim e um funcionário da FUNAI, que diante da minha inquietude, sugeriu fazer um trabalho diferenciado para inserir a comunidade escolar não indígena no cotidiano dos seus colegas indígenas na aldeia Jerusalém, propiciando em contrapartida uma maior inclusão na Escola em Sítio Novo.

Sendo o debate da alteridade tão recente entre nós, esse projeto teve como proposta uma alternativa de mudança de mentalidades: respeito ao outro, tolerância, quebra de preconceito e 
diálogo intercultural da sociedade sítio-novense com as sociedades indígenas do entorno (Krikati e Guajajara).

A alteridade não é algo novo. A diferença acompanha o desenvolvimento da humanidade e é um assunto muito discutido hoje, porque primeiro se falava dos povos puros. Hoje todas as etnias são híbridos culturais. Estão traduzidas. A discussão mais atual é o resgate, a conservação e a preservação. Resgate da natureza, da moral humana e da cultura em geral.

Identidade e diferença são temas indissociáveis. A identidade faz com que você reconheça quem você é, de qual grupo faz parte. Ela referencia você e o outro no convívio social, desde um simples "me chamo José ou Maria", ou, "sou judeu, negro, índio". Isso é identificação de etnias. O fato de ser índio me diferencia dos outros grupos que compõem a sociedade? Nesse tipo de interrogação reconhecemos que o outro é uma alteridade, que caracterizamos o que é outro, o diferente, ou seja, o contrário da identidade.Conforme afirma Roberto Cardoso de Oliveira:

A identidade e a diferença estão em estreita conexão com as relações de poder. O poder de definir a identidade e de marcar a diferença não pode ser separado das relações mais amplas de poder. A identidade e a diferença não são nunca inocentes. Afirmar a identidade significa demarcar fronteiras, significa fazer distinções entre o que fica dentro e o que fica fora. (2006, p.81-82).

Daí a necessidade de trabalhar a mudança de mentalidades, pois houve a inserção de uma nova cultura, de um povo que é alvo de preconceitos e discriminação pela sociedade desde a conquista dos Europeus aqui no Brasil em 1500. Faz-se necessário mostrar que a alteridade é algo positivo, que ser diferente não significa ser inferior. Precisamos urgentemente desconstruir esses estigmas que nossos irmãos indígenas sofreram e sofrem.

Os povos indígenas têm travado uma dura batalha na busca pelos seus direitos. Existem algumas vitórias, porém a estrada para a efetivação desses direitos é longa. Conforme o PPA 2012-2015, cabe ao MEC coordenar as ações de educação indígena em um regime de colaboração com estados e municípios e em articulação com a FUNAI.

As proposições do MEC referentes à educação escolar indígena nos estados têm sido tratadas como ações pontuais, faltando-lhes continuidade e diálogo com a sociedade em geral. Por 
seu baixo êxito, são incapazes de efetivarem os direitos consagrados em textos legais. Existe um grande entrave à aplicação das leis, normas e diretrizes da educação, sendo necessária uma revisão das responsabilidades previstas em lei e dos instrumentos administrativos existentes visando à efetividade na execução das ações pertinentes.

Falar de democracia, cidadania, inclusão é muito bonito. $\mathrm{Na}$ prática as coisas são bem diferentes. Os valores capitalistas dão as cartas em nossa sociedade. Os grupos dominantes historicamente têm se apossado da riqueza, das oportunidades, do poder de decidir, sem levar em consideração a vida, as necessidades, a dignidade do ser humano. As populações estigmatizadas estão à mercê da intolerância étnico-racial e são um peso para os grupos que dominam a sociedade urbano-industrial.

Como argumenta Bobbio:

(...) a democracia é subversiva. E é subversiva no sentido mais radical da palavra porque, onde chega, subverte a concepção tradicional de poder — tão tradicional que chega a ser considerada natural segundo a qual o poder - político ou econômico, paterno ou sacerdotal — desce do alto para baixo. (1983, p. 64)

Existe um preconceito gigante para com os povos indígenas. Em geral são rotulados de adjetivos que os depreciam simplesmente pelo fato dos mesmos não serem interessantes para a elite do nosso país. São classificados como os 'sobrantes'. Dentro da escola, por diversas vezes, encontrei docentes e discentes discriminando e classificando os mesmos de adjetivos pejorativos.

A realidade escolar dessa etnia é muito precária. Apesar do MEC e dos Estados e municípios garantirem que a educação tem qualidade, o que se tem é uma educação básica de má qualidade, sem reflexão das peculiaridades e da especificidade desses povos.

\section{(1) A situação atual da educação escolar indígena:}

a. Na maioria dos casos a educação básica funciona na própria aldeia, com professores indígenas e não-indígenas, mas, devido à falta de fiscalização do Estado, a escola funciona de forma precária e, em alguns casos, a escola nem funciona.

b. Os professores indígenas não têm qualificação formal 
requerida para lecionar as disciplinas comuns à nossa sociedade e, assim, perdem suas vagas para os não-índios, a partir do ensino fundamental maior e médio, quadro que está mudando aos poucos devido ao Curso de Licenciatura em Educação Intercultural da UFG (Universidade Federal de Goiás) e, a partir de 2016, na UEMA (Universidade Estadual do Maranhão).

c. A maioria das escolas é improvisada, geralmente um galpão coberto de palha, onde também funcionam a igreja, o centro comunitário. $\mathrm{O}$ número de carteiras é insuficiente e muitas vezes os alunos trazem cadeiras de casa.

d. A merenda escolar é entregue de forma irregular, podendo ficar períodos de até 03 meses sem receberem os gêneros alimentícios, além do que a merenda não é suficiente para o mês. Os indígenas relatam que em governos anteriores a merenda chegava vencida ou muito perto de vencer.

Com todos esses percalços aqueles discentes que conseguem terminar o ensino fundamental, nesse caso específico da Aldeia Jerusalém, são direcionados ao ensino médio na cidade mais próxima. Encontram uma situação de total exclusão, onde a sociedade envolvente está carregada de "pré-conceitos" e não respeitam as diferenças e não compreendem o outro.

Precisamos dar um basta nessa situação. Não são só os indígenas que sofrem preconceito. Todos os 'sobrantes' (camponeses, indígenas, pobres, negros, quilombolas ....). Na era da inclusão a educação tem que ser o meio transformador das mentalidades discriminatórias.

\section{(2) As diferenças e as parecenças entre alunos indígenas Krikati e não-indígenas no C. E. Parsondas de Carvalho}

O projeto com o título "As Diferenças e Parecenças entre alunos indígenas Krikati e não-indígenas no C. E. Parsondas de Carvalho" começou em 2012 e terminou em 2014, e teve como objetivo: Erradicar ou diminuir o preconceito e a discriminação que a sociedade indígena sofre no município de Sítio Novo e 
especialmente no Centro de Ensino Parsondas de Carvalho demonstrando à sociedade do entorno a relevância do outro em todas as suas especificidades.

E de maneira específica:

a. Identificar e apreender a percepção dos estudantes em relação à cultura dos Krikati.

b. Ministrar palestras expositivas sobre Direitos Humanos e a importância da preservação da cultura do outro. c. Realizar atividades extra-sala, como uma visita a aldeia Jerusalém, próxima ao município de Sítio Novo. d. Realizar uma oficina de artesanato na Escola Parsondas de Carvalho, na qual os Krikati demonstrariam a confecção de seus artesanatos e suas pinturas corporais.

e. Que essa proposta de ação possa levar essa comunidade à reflexão crítica, meta maior dos Direitos Humanos.

De todas essas ações, somente uma não foi realizada, uma oficina de artesanato na Escola Parsondas de Carvalho, na qual os Krikati ensinariam a fazer seus artesanatos e suas pinturas). As demais foram desenvolvidas com sucesso.

Iniciamos o projeto com uma visita somente com os alunos do terceiro ano do ensino médio, para uma conversa informal, uma visita aos colegas de sala. Logo depois, fizemos um grande evento com todos os alunos, professores e a gestora do C. E. Parsondas de Carvalho, além de um representante da FUNAI e outros convidados, na aldeia Jerusalém.

O encontro teve uma programação diversificada, ressaltando as características de cada cultura: torneio de futebol e vôlei; uma demonstração da corrida de tora; algumas índias demonstraram sua arte em grafismo com as pinturas corporais; brincadeiras recreativas para com as crianças; brincadeira cultural da bananeira; almoço coletivo; lanche coletivo e o encerramento com uma emocionante cantoria do povo Krikati. Tivemos ainda palestras na Escola sobre as questões de alteridade, hibridismo, diferenças e direitos humanos.

$\mathrm{O}$ resultado foi extremamente positivo. Houve interação entre os discentes. Os alunos indígenas não eram mais excluídos dos grupos e das atividades da Escola. O preconceito foi sendo 
substituído por admiração à cultura e aos costumes do povo Krikati. O corpo docente se despiu da arrogância e do preconceito e começou a tentar entender as especificidades dos alunos indígenas.

Essa troca de conhecimentos é, sem dúvida, uma genuína prática da interculturalidade que deve ser cultivada para que o preconceito seja erradicado e para que haja mudança de mentalidade e de comportamento em relação aos povos indígenas do Brasil e do mundo.

Como argumenta Gallois:

Contrapor diversidade e diferença cultural pode ser oportuno para abordar o novo perfil das sociedades indígenas e os espaços políticos que elas reivindicam, nesse momento histórico em que sua posição de "tutelados " está sendo revisada. Momento histórico em que a maior parte da população brasileira ainda hesita em perceber que os índios, definitivamente, não estão nem se assimilando nem desaparecendo da cena nacional. Nessa abordagem o contato ao invés de representar um problema - do qual derivaria o "problema indígena" - é um espaço para a enunciação ativa de diferenças, em âmbitos multi -locais.

O C. E. Parsondas de Carvalho continua recebendo alunos da etnia Krikati e ainda hoje colhemos os frutos do projeto. Houve mudança na forma de pensar e agir dos docentes, levando em consideração que são eles os mediadores para que o processo de ensino aprendizagem possa acontecer. Esse projeto foi só uma sementinha lançada por uma inquietação de uma estudiosa dos povos nativos do nosso país e precisa ser contínuo, diante deste cenário de exclusão.

\section{CONSIDERAÇÕES FINAIS}

Em tempo em que se fala tanto em liberdade e quebra de preconceitos é importante ter respeito ao próximo com todas as suas diferenças, pois não se pode manter uma identidade na falência do outro. O desprezo e o desrespeito ferem a moral de qualquer etnia, através da negação do reconhecimento à cultura do outro. Mesmo 
em um mundo globalizado sempre haverá espaço para a diversidade étnica e cultural.

É preciso preservar não só a história cultural das classes privilegiadas, do branco, do homem, do colonizador. Faz-se necessário preservar as identidades do povo brasileiro, que é multicultural, onde estão inseridos o indígena, a mulher, o negro, o pobre, enfim todos os que foram excluídos durante todo o período da história tradicional.

\section{REFERÊNCIAS}

BOBBIO, Norberto. Quais alternativas à democracia representativa? In: BOBBIO, Norberto. Qual socialismo? Discussão de uma alternativa. $4^{\mathrm{a}} \mathrm{ed}$. Rio de Janeiro, Paz e Terra, 2001.

CARDOSO DE OLIVEIRA, Roberto. Caminhos da identidade: Ensaios sobre etnicidade e multiculturalismo. São Paulo: Editora UNESP, Brasil a: paralelo 15. 2006.

TILKIN, Dominique Gallois (2000). Travessia. Revista do migrante, ano $\mathrm{XII} / 36.2000(5-10)$. 